\title{
THE USE OF ASYMPTOTIC FUNCTIONS FOR DETERMINING EMPIRICAL VALUES OF CN PARAMETER IN SELECTED CATCHMENTS OF VARIABLE LAND COVER
}

\author{
ANDRZEJ WAŁĘGA, DARIUSZ MŁYŃSKI \\ University of Agriculture in Kraków, Department of Sanitary Engineering and Water Management, \\ e-mail: a.walega@ur.krakow.pl \\ KATARZYNA WACHULEC \\ DHI Poland, o/Kraków, \\ e-mail: a.walega@ur.krakow.pl,pl78114@dhigroup.com,darowad@wp.pl
}

\begin{abstract}
The aim of the study was to assess the applicability of asymptotic functions for determining the value of $C N$ parameter as a function of precipitation depth in mountain and upland catchments. The analyses were carried out in two catchments: the Rudawa, left tributary of the Vistula, and the Kamienica, right tributary of the Dunajec. The input material included data on precipitation and flows for a multi-year period 1980-2012, obtained from IMGW PIB in Warsaw. Two models were used to determine empirical values of $C N_{\text {obs }}$ parameter as a function of precipitation depth: standard Hawkins model and 2-CN model allowing for a heterogeneous nature of a catchment area.

The study analyses confirmed that asymptotic functions properly described $P-C N_{\text {obs }}$ relationship for the entire range of precipitation variability. In the case of high rainfalls, $C N_{\mathrm{obs}}$ remained above or below the commonly accepted average antecedent moisture conditions AMCII. The study calculations indicated that the runoff amount calculated according to the original SCS-CN method might be underestimated, and this could adversely affect the values of design flows required for the design of hydraulic engineering projects. In catchments with heterogeneous land cover, the results of $C N_{\text {obs }}$ were more accurate when 2-CN model was used instead of the standard Hawkins model. 2-CN model is more precise in accounting for differences in runoff formation depending on retention capacity of the substrate. It was also demonstrated that the commonly accepted initial abstraction coefficient $\lambda=0.20$ yielded too big initial loss of precipitation in the analyzed catchments and, therefore, the computed direct runoff was underestimated. The best results were obtained for $\lambda=0.05$.
\end{abstract}

Key words: direct runoff, standard behavior, 2-CN model, SCS-CN method

\section{INTRODUCTION}

Proper estimation of direct runoff in an ungauged catchment is crucial for design of flood protection objects. It is usually based on rainfall-runoff models that use the intensity of an effective rainfall as input data. The Soil Conservation Service Curve Number (SCS-CN) method [29], (now National Resources Conservation Service NRCS) is one of the most popular methods for computing the surface runoff depth for a given rainfall event from small catchments [17], [30]. This method represents an event-based lumped conceptual approach [33]. The SCS-CN is a very simple and easy to apply method developed for predicting surface runoff from hortonian overland flow dominated catchments. The primary reason for its wide applicability and acceptability is the fact that it accounts for major runoff generating catchment characteristics, namely soil type, land use/treatment, surface condition and antecedent moisture condition [1], [4], [5], [10], [16], [19], [25]. The $C N$ values can be obtained from tables according to NEH4, however, $\mathrm{CN}$ estimation based on real data from local or nearby similar catchments is preferable [28].

Although several modifications to this method have been suggested and reported in literature [6], [14], [19], [31], further improvements are still needed. The greatest limitations of the original NRCS CN method are as follows. The three AMC levels used with this method permit unreasonable sudden jumps in $\mathrm{CN}$ and hence, corresponding sudden jumps in the computed runoff are possible, there is a lack of clear guidance on how to vary antecedent moisture conditions, 
and there is no explicit dependency between the initial abstraction and the antecedent moisture [26]. As mentioned in numerous studies [3], [15], [25], $C N$, according to $S C S$, is significantly different from the one calculated empirically, based on the recorded rainfall-runoff events. Hawkins [11] claimed that runoff values obtained from the SCS-CN method were extremely sensitive to changes in $\mathrm{CN}$ and it was difficult to accurately select $\mathrm{CN}$ from available handbook tables. $C N$ is estimated most successfully for traditional agricultural catchments while the assessments for semiarid rangelands and for forest catchments are not as successful [31]. Secondary systematic correlation usually emerged in the catchments between the calculated $C N$ and the rainfall depth. In most catchments, the calculated $C N$ approached a constant value with increasing rainfall depth.

Many designers unknowingly use the original method in their hydrological calculations, which may result in a significant underestimation of the actual flood parameters [14]. Therefore, it seems necessary to verify the application of the SCS-CN approach in local conditions to reduce the uncertainty of modeling results and to promote more common use of this method in practice.

The aim of the study was to assess the applicability of asymptotic functions for determining the value of $C N$ parameter as a function of precipitation depth in mountain and highland catchments. The study was carried out for two catchments located in the south of Poland: the Rudawa and the Kamienica. It was aimed at verification of three following research hypotheses. The first one was whether the use of asymptotic functions enables to determine empirical values of $C N$ parameter that are much more accurate for the assessment of surface runoff formation than $C N$ values yielded by the original method, the second was whether $C N$ parameter significant correlates with precipitation depth, and the last one was whether in the catchments of diversified land use, empirical values of $C N$ parameter determined with $2-\mathrm{CN}$ method provide better results than $C N$ defined as a weighted average value for the entire catchment.

\section{MATERIALS AND METHODS}

The study involved two catchments located in the upper Vistula river basin: the Rudawa, left tributary of the Vistula, and Kamienica, right tributary of the Dunajec (Fig. 1). As far a high flows are concerned, the hydrological regime of the investigated catchments is free from anthropogenic pressure.

The Kamienica catchment is a mountain one. Its area to Łabowa gauging station is $64.878 \mathrm{~km}^{2}$. The catchment is covered mainly by forests (ca. 76.4\%), predominantly coniferous ones. Arable lands take up ca. $23.2 \%$, and the rest (ca. 0.4\%) is an anthropogenic area. The upland catchment of the Rudawa has an area of $282.664 \mathrm{~km}^{2}$ to the Balice gauging station. Majority of its area is covered by arable lands (ca. 65\%). A large part (ca. 26.6\%) is covered by forests, dominated by deciduous species. The rest (ca. $8.4 \%$ ) is an anthropogenic area.

Basic catchment characteristics are presented in Table 1.

The initial data on measured precipitation and storm event runoff values for the analyzed catchments were obtained from the Institute of Meteorology and Water Management, National Research Institute in Warsaw, Poland. Twenty-four-hour time step data were used for both the precipitation and runoff recorded in the years 1980-2012. The runoff data were measured at the river gauging stations located in the catchments, i.e., Labowa for the Kamienica river and Balice for the Rudawa river. Areal curve reduction method was used to assess the average precipitation [33]. Before the actual analysis, individual storm event hydrograph data were separated into the base flow and direct runoff by drawing a straight line on a hydrograph from the point where the flow starts to increase to the point on the descending part where the direct runoff ends [21]. This procedure allowed to determine the actual amount of the direct runoff layer for individual episodes.

A general form of the SCS-CN model is expressed by the following equations:

Table 1. Basic characteristics of the analyzed catchments

\begin{tabular}{|l|c|c|c|}
\hline \multicolumn{1}{|c|}{ Characteristic } & Unit & $\begin{array}{c}\text { Kamienica } \\
\text { catchment }\end{array}$ & $\begin{array}{c}\text { Rudawa } \\
\text { catchment }\end{array}$ \\
\hline Area & $\mathrm{km}^{2}$ & 64.878 & 282.664 \\
\hline Length of main river & $\mathrm{km}$ & 13.359 & 26.006 \\
\hline Length of river network & $\mathrm{km}$ & 42.149 & 137.157 \\
\hline Density of river network & $\mathrm{km} \mathrm{km}^{-2}$ & 0.650 & 0.485 \\
\hline Average altitude of catchment & $\mathrm{m}$ a.s.l. & 695 & 351 \\
\hline Average slope of catchment & $\%$ & 29.42 & 11.53 \\
\hline
\end{tabular}




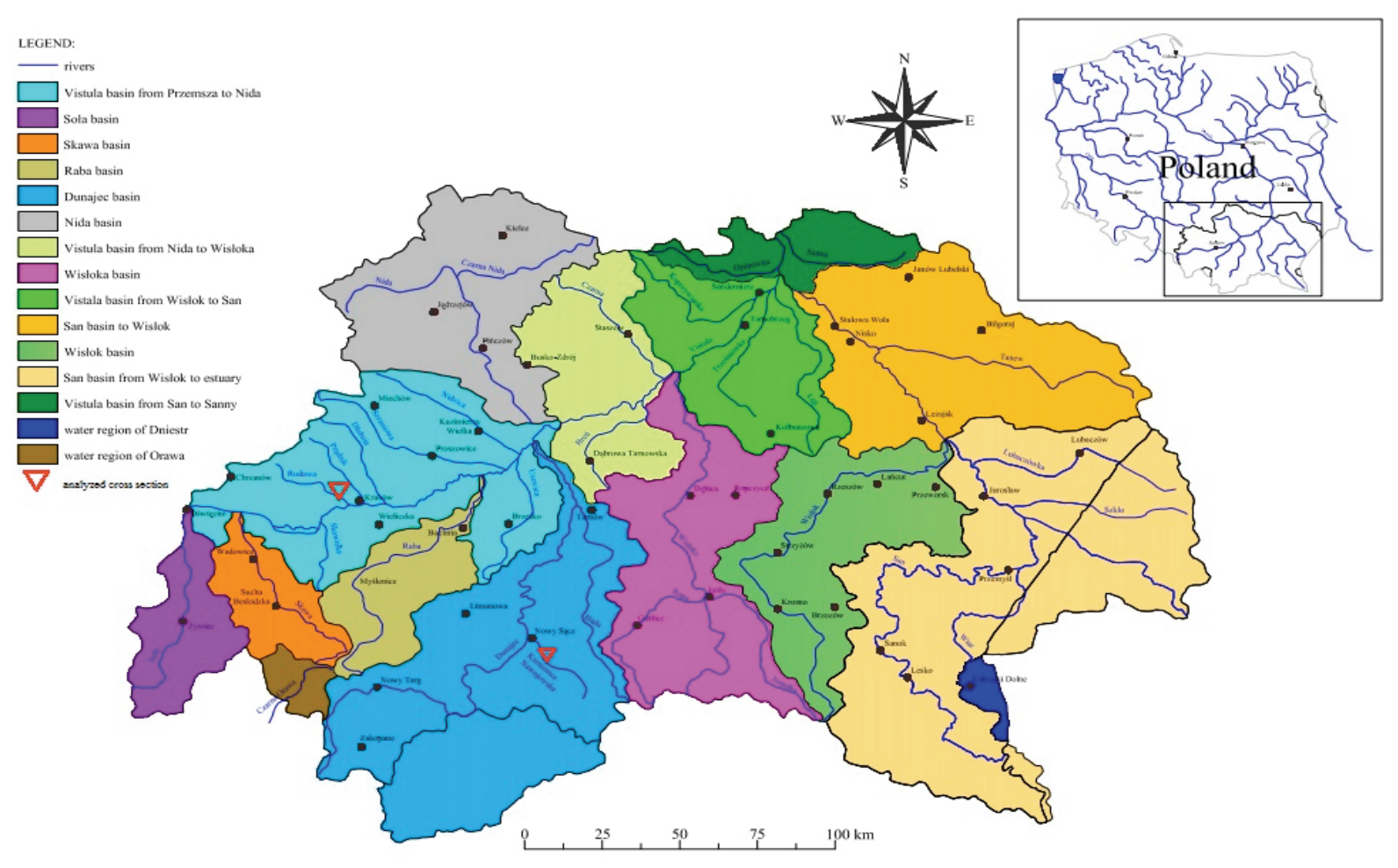

Fig. 1. Location of the analyzed catchments

$$
\begin{aligned}
& Q=\frac{\left(P-I_{a}\right)^{2}}{P-I_{a}+S} \text { if } P>I_{a}, \\
& Q=0 \text { otherwise } I_{a}=\lambda S,
\end{aligned}
$$

where: $Q$ - direct runoff (mm), $P$ - total precipitation $(\mathrm{mm}), I_{a}$ - initial abstraction $(\mathrm{mm}), S$ - potential maximum retention $(\mathrm{mm})$ and $\lambda-$ initial abstraction coefficient (dimensionless).

The parameter $S$ is expressed as:

$$
S=\frac{25400}{C N}-254
$$

where $S$ is expressed in mm and $C N$ is the curve number which depends on the soil type, land cover and land use, hydrological conditions, and antecedent moisture condition (AMC).

The measured $P$ and $Q$ values for each catchment were sorted separately and realigned on a rank order basis to form $P-Q$ pairs of equal return period, following the frequency matching technique [11].

Observed values of curve number, $C N_{\text {obs }}$, were determined based on the $P-Q$ pairs. The following equation was used to calculate the real value of potential maximum retention $S_{\text {obs }}$ [7]:

$$
S_{\text {obs }}=\frac{P}{\lambda}+\frac{(1-\lambda) Q-\sqrt{(1-\lambda)^{2} Q^{2}+4 \lambda P Q}}{2 \lambda^{2}},
$$

where: $P$ - total precipitation amount causing flow event [mm], $Q$ - direct runoff [mm], $\lambda$ - initial abstraction coefficient (dimensionless). The observed value of $C N, C N_{\text {obs }}$ parameter was calculated according to the formula [8]:

$$
C N_{\text {obs }}=\frac{25400}{254+S_{\text {obs }}}
$$

However, even when the $C N$ is determined from measured $P-Q$ data, the $C N$ values calculated with Eq. (5), in fact, vary significantly from storm to storm on any catchment. For this reason, to estimate a single $C N$ value describing the catchment in terms of measured runoff data, two models based on asymptotic functions were proposed: Hawkins model [11] and 2-CN model [27].

Standard asymptote model described by Hawkins [11] is summarized by the following formula:

$$
C N(P) 1=C N_{\infty}+\left(100-C N_{\infty}\right) \cdot \exp (-k \cdot P)
$$

where:

$C N_{\infty}$ - constant value approached as $P \rightarrow \infty$,

$k$ - fitting constant.

In most catchments, these calculated $C N \mathrm{~s}$ approached a constant value with increasing rainfall depth that was assumed to characterize the catchment [11], [27]. The three different patterns of $C N-P$ relationship can be described as follows: "standard be- 
havior" when small rainfall depths correspond to greater values of calculated $C N \mathrm{~s}$ which decline progressively along with increasing storm size, approaching a stable, nearly constant asymptotic $C N$ along with increasingly larger storms; "complacent behavior" when the observed $C N$ declines steadily within increasing rainfall, with no appreciable tendency to approach a constant value; and "violent behavior" when the calculated $C N$ has an apparent constant value for all rainfall depths, except for very low rainfall depths, where $C N$ suddenly increases.

In the next paragraph the $C N$ concept [27] was described.

The idea of dividing the catchment into two homogeneous sub-areas originated from the following research hypothesis that during a rainfall event the surface runoff is first formed in the areas characterized by lower permeability, i.e., smaller storage capacity. Then, when the rainfall event continues, the runoff is also formed in the permeable areas. The maximum runoff is observed when the flow occurs throughout the catchment area. Considering the above, the amount of runoff from two homogeneous areas can be calculated based on the following relationships:

$$
\begin{gathered}
Q=Q_{a} \quad \text { if } \quad \lambda S_{a} \leq P<\lambda S_{b}, \\
Q=Q_{a}+Q_{b} \quad \text { if } P \geq \lambda S_{b}, \\
Q=0 \text { otherwise, } \\
Q_{a}=a \cdot \frac{\left(P-\lambda S_{a}\right)^{2}}{P+(1-\lambda) \cdot S_{a}}, \\
Q_{b}=(1-a) \cdot \frac{\left(P-\lambda S_{b}\right)^{2}}{P+(1-\lambda) \cdot S_{b}} .
\end{gathered}
$$

The empirical $P-C N_{\text {obs }}$ relationship was approximated with the modified SCS-CN method (model 1), using the following equation [27]:

$$
\begin{gathered}
C N(\mathrm{~m} 2)= \\
\frac{25400}{5 \cdot\left[P+2 \cdot\left(Q_{a}+Q_{b}\right)\right.} \\
-\sqrt{4 \cdot\left(Q_{a}+Q_{b}\right)^{2}+5 \cdot P \cdot\left(Q_{a}+Q_{b} 0\right]}+254
\end{gathered}
$$

where $S_{a}$ and $S_{b}$ are the potential maximum retention values corresponding to the two homogeneous sub-areas characterized by $C N_{a}$ and $C N_{b}$ values respectively, $a$ is an area fraction of the catchment with $C N=C N_{a}$, then $(1-a)$ is the area fraction of the catchment with $C N=C N_{b}, Q_{a}$ and $Q_{b}$ were determined based on equations (10) and (11). The parame- ters subjected to optimization in this model were $C N_{a}$ and $C N_{b}$. Parameter $a$ was identified by an analysis of main land cover using GIS.

To investigate the consequences of spatial variability on the $C N$ vs. $P$ relationship in the catchment, a simplified approach was adopted. First, the catchment was divided into two areas characterized by relatively similar land use. Then, two $C N$ values $C N_{a}$ and $C N_{b}$, with $C N_{a}>C N_{b}$, were determined for these areas. If a denotes the area fraction of the catchment with $C N=C N_{a}$, then $(1-a)$ is the area fraction of the catchment with $C N=C N_{b}$. It seems obvious that $C N$ must be treated as constant for a relatively homogeneous soil-cover complex [31].

To determine the amount of initial abstraction, all calculations were performed for various values of $\lambda$. In the present study, the model performance was assessed with root mean square error (RMSE), Nash-Sutcliffe model efficiency (EF) [20]. RMSE and $E F$ were expressed as below:

$$
\begin{gathered}
R M S E=\sqrt{\frac{1}{N} \cdot \sum_{i=1}^{N}\left(Q_{\mathrm{obs}, i}-Q_{\mathrm{cal}, i}\right)^{2},} \\
E F=1-\frac{\sum_{i=1}^{N}\left(Q_{\mathrm{obs}, i}-Q_{\mathrm{calc}, i}\right)^{2}}{\sum_{i=1}^{N}\left(Q_{\mathrm{obs}, i}-\overline{Q_{\mathrm{obs}}}\right)^{2}},
\end{gathered}
$$

where $R M S E$ is expressed in $\mathrm{mm}, E F$ is dimensionless. $Q_{\text {obs }}$ is the observed storm runoff [mm], $Q_{\text {calc }}$ is the calculated runoff $[\mathrm{mm}], \overline{Q_{o b s}}$ is a mean of the observed runoff values in the catchment, $N$ is the total number of rainfall-runoff events, and $i$ is an integer varying from 1 to $N$.

\section{RESULTS AND DISCUSSION}

Tables 2-4 show basic characteristics of rainfallrunoff events in the analyzed catchments. The calculations of $C N$ parameter allowed for two coefficients of initial abstraction, $\lambda=0.05$ and 0.20 . In the catchment of the mountain river Kamienica, a clearly asymmetric (right-hand skewed) and leptokurtic distribution of precipitation and direct runoff was observed. As far as flows were concerned, this was a typical pattern for mountain catchments. The Kamienica catchment featured the greatest differences between the mean and the median, especially in the case of rainfall. In the upland catchment of the Rudawa, similar patterns were observed for rainfall and runoff, but with much smaller runoff asymmetry. It can, 
Table 2. Characteristics of rainfall-runoff events in the Kamienica catchment

\begin{tabular}{|l|c|c|c|c|c|c|}
\hline \multicolumn{1}{|c|}{ Statistics } & $P$ & $Q_{\text {obs }}$ & $\begin{array}{c}S_{\text {obs according }} \\
\text { to Eq. (4) } \\
\text { for } \lambda=0.20\end{array}$ & $\begin{array}{c}C N_{\text {obs }} \text { according } \\
\text { to Eq. (5) } \\
\text { for } \lambda=0.20\end{array}$ & $\begin{array}{c}S_{\text {obs }} \text { according to } \\
\text { Eq. (4) } \\
\text { for } \lambda=0.05\end{array}$ & $\begin{array}{c}C N_{\text {obs }} \text { according } \\
\text { to Eq. (5) } \\
\text { for } \lambda=0.05\end{array}$ \\
\hline \multicolumn{1}{|c|}{ Number of events } & \multicolumn{5}{|c|}{27} \\
\hline Mean [mm] & 30.7 & 56.9 & 32.7 & 88.6 & 43.6 & 85.4 \\
\hline Min [mm] & 12.7 & 28.6 & 20.4 & 85.0 & 27.9 & 81.8 \\
\hline Max [mm] & 81.1 & 122.3 & 45.0 & 92.6 & 56.5 & 90.1 \\
\hline Median [mm] & 28.3 & 56.2 & 34.9 & 87.9 & 46.5 & 84.5 \\
\hline Standard deviation [mm] & 16.057 & 22.666 & 7.161 & 2.233 & 8.746 & 2.549 \\
\hline Coeffic. of variability & 0.523 & 0.399 & 0.219 & 0.025 & 0.201 & 0.030 \\
\hline Skewness & 1.735 & 1.252 & -0.326 & 0.389 & -1.101 & -1.062 \\
\hline Kurtosis & 3.462 & 1.944 & -1.036 & -1.037 & -0.525 & 0.582 \\
\hline 25th percentile [mm] & 18.600 & 39.700 & 26.738 & 86.880 & 36.137 & 83.386 \\
\hline 75th percentile [mm] & 37.900 & 69.200 & 38.359 & 90.476 & 50.608 & 87.545 \\
\hline
\end{tabular}

Table 3. Characteristics of rainfall-runoff events in the Rudawa catchment

\begin{tabular}{|c|c|c|c|c|c|c|}
\hline Statistics & $P$ & $Q_{\text {obs }}$ & $\begin{array}{c}S_{\text {obs }} \text { according } \\
\text { to Eq. }(4) \\
\text { for } \lambda=0.20\end{array}$ & $\begin{array}{c}C N_{\text {obs }} \text { according } \\
\text { to Eq. }(5) \\
\text { for } \lambda=0.20\end{array}$ & $\begin{array}{c}S_{\text {obs }} \text { according to } \\
\text { Eq. (4) } \\
\text { for } \lambda=0.05\end{array}$ & $\begin{array}{c}C N_{\text {obs }} \text { according } \\
\text { to Eq. }(5) \\
\text { for } \lambda=0.05\end{array}$ \\
\hline Number of events & \multicolumn{6}{|c|}{14} \\
\hline Mean $[\mathrm{mm}]$ & 9.0 & 38.6 & 56.5 & 82.3 & 95.5 & 73.6 \\
\hline $\operatorname{Min}[\mathrm{mm}]$ & 3.4 & 11.6 & 14.0 & 72.8 & 21.9 & 63.0 \\
\hline $\operatorname{Max}[\mathrm{mm}]$ & 22.4 & 77.6 & 94.8 & 94.8 & 149.4 & 92.0 \\
\hline Median [mm] & 7.8 & 38.4 & 61.2 & 80.6 & 103.9 & 71.0 \\
\hline Standard deviation $[\mathrm{mm}]$ & 5.001 & 17.515 & 23.372 & 6.470 & 38.943 & 9.010 \\
\hline Coeffic. of variability & 0.557 & 0.454 & 0.414 & 0.079 & 0.408 & 0.122 \\
\hline Skewness & 3.144 & 0.652 & -0.209 & 0.009 & -0.172 & 0.396 \\
\hline Kurtosis & 1.549 & 0.413 & -0.517 & 0.809 & -0.755 & 1.117 \\
\hline 25 th percentile $[\mathrm{mm}]$ & 5.350 & 23.800 & 36.960 & 78.423 & 64.178 & 67.923 \\
\hline 75th percentile $[\mathrm{mm}]$ & 10.925 & 51.450 & 69.924 & 87.299 & 120.015 & 79.839 \\
\hline
\end{tabular}

therefore, be assumed that the hydrological regime of the Rudawa is much more stable and predictable than that of the Kamienica. Lower variability of the Rudawa catchment, particularly with reference to direct runoff, was also confirmed by lower values of kurtosis and coefficient of variation. $C N$ values for both $\lambda$ thresholds were higher in the Kamienica catchment, which indicated a greater potential for the formation of surface runoff in the mountain than in the upland catchment. Karst substrate present in the Rudawa catchment further improved its retention capacity and, therefore, lower $C N$ values might be obtained. In general, variation in $C N$ values was very low in both catchments but it was slightly greater in the Rudawa catchment. In the catchment of the Rudawa, runoff formation depended mainly on the substrate moisture conditions prior to a runoff event. In the catchment of the Kamienica, where the flysch substrate was poorly permeable, the antecedent moisture content was of smaller importance. Therefore, it can be concluded that a mountain catchment is always conducive to runoff formation, whereas in an upland catchment the role of antecedent moisture conditions (AMC) is more important due to greater substrate permeability. This was confirmed by differences between the values of $C N$ parameter depending on $\lambda$. Higher values of this parameter indicated greater initial abstraction due to infiltration, evapotranspiration, interception or surface retention. In the mountain catchment, mean difference in $C N$ parameter for different $\lambda$ was $3.6 \%$ and in the catchment of the Rudawa it was $10.5 \%$.

According to the assumptions outlined in Materials and Methods chapter, two models were used to describe empirical variability of $C N_{\text {obs }}$ as a function of 
rainfall depth causing direct runoff. First, rainfallrunoff episodes were selected for each catchment and then Hawkins's [11] assumptions were used to match $P-Q$ pairs and calculate empirical values of $C N_{\text {obs }}$. A total of 27 rainfall-runoff episodes were selected for the Kamienica catchment and 14 for the Rudawa. The analyses were performed for two initial abstraction coefficients $\lambda=0.05$ and 0.20 . Figure 2 presents the relationship between $C N_{\text {obs }}$ and $P$ for two values of $\lambda$ and approximation of variables with standard Hawkins model (model 1) in the Kamienica catchment. The figure indicates that model 1 correctly approximated the empirical data for both values of $\lambda$. A relationship between rainfall depth and $C N_{\text {obs }}$ was observed, wherein increasing $P$ was accompanied by a reduction in $C N_{\text {obs }}$. However, clear stabilization of $C N$ for high rainfall described by other authors [3], [5], [13] was not observed. Therefore, it seems to be rather the type of relationship Hawkins [11] described as "complacent" behavior. Similar relationships were found in microcatchments of southern Poland [14]. It was suggested that the $P-C N_{\text {obs }}$ relationship might be a result of different runoff triggering processes, such

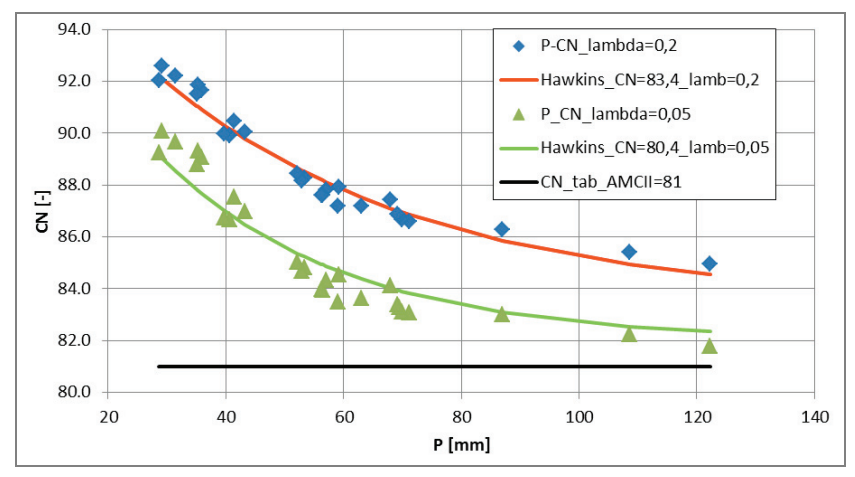

Fig. 2. $C N-P$ relationship for various values of the initial abstraction coefficient yielded by model 1 in the Kamienica catchment

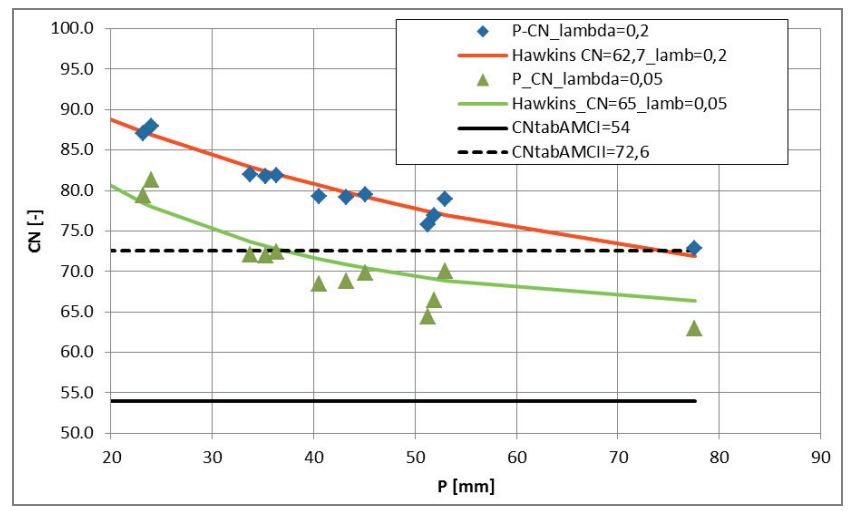

Fig. 3. $C N-P$ relationship yielded by model 1 in the Rudawa catchment for various values of the initial abstraction coefficient as overland flow and rapid subsurface flow or a small rainfall that may cause a surface runoff when a catchment is characterized by a high moisture level or poor permeability. As a result, small precipitations are associated with high $C N_{\text {obs }}$ values. However, high values of $C N_{\text {obs }}$ during small precipitation may also occur when the rain reaches the soil covered with a nonpermeable layer formed due to long-lasting drought. Similar relationships were observed for the catchment of the Rudawa (Fig. 3).

The analyses were then used to develop detailed $P-C N_{\text {obs }}$ relationships as per the standard model that looks as follows:

The Kamienica catchment:

$$
\begin{gathered}
C N(P)=83.4+(100-83.4) \exp \left(\frac{-P}{45.1}\right) \\
\text { for } \lambda=0.20, \\
C N(P)=82.0+(100-82.0) \exp \left(\frac{-P}{31.1}\right) \\
\text { for } \lambda=0.05 .
\end{gathered}
$$

The Rudawa catchment:

$$
\begin{gathered}
C N(P)=62.7+(100-62.7) \exp \left(\frac{-P}{55.3}\right) \\
\text { for } \lambda=0.20, \\
C N(P)=65.0+(100-65.0) \exp \left(\frac{-P}{24.2}\right) \\
\text { for } \lambda=0.05 .
\end{gathered}
$$

The quality of description of $P-C N_{\text {obs }}$ relationship with model 1 is presented in Table 5 . The analyses revealed slightly better model accuracy for $\lambda=0.20$. Ritter and Muñoz-Carpena [24] established a hydrological model performance rating criteria where $E F<0.5$ was deemed a lower threshold for unsatisfactory. Other model performance ratings were as follows: acceptable $(0.65 \leq E F<0.80)$, good $(0.80 \leq E F<0.90)$, and very good $(E F>0.90)$. Based on these criteria, model 1 for the catchments of the Kamienica and the Rudawa was very good. Only for $\lambda=0.05$ in the catchment of the Rudawa the model was good. Figures 2 and 3 show a theoretical value of the $C N$ according to the tables of the original $S C S-C N$ method [29]. For design purposes, the reliable value of $C N_{\text {obs }}$ should be the one for the highest precipitation. In the model 1, it is $C N_{\infty}$. In the Kamienica catchment, the values of $C N_{\infty}$ were higher than $C N_{\text {theor }}$ determined for AMCII, and in the Rudawa catchment they were between AMCI and II. These results indicated that measures should be taken to accurately determine 
Table 4. 2-CN model parameters in the analyzed catchments

\begin{tabular}{|c|c|c|c|c|c|c|c|c|}
\hline \multirow{2}{*}{$\begin{array}{c}\text { Coefficient } \\
\text { of initial } \\
\text { abstraction }\end{array}$} & \multicolumn{4}{|c|}{ The Kamienica catchment } & \multicolumn{4}{c|}{ The Rudawa catchment } \\
\cline { 2 - 9 } & $a$ & $C N_{a}$ & $C N_{b}$ & $C N_{\infty}$ & $a$ & $C N_{a}$ & $C N_{b}$ & $C N_{\infty}$ \\
\hline$\lambda=0.20$ & 0.483 & 85.1 & 62.7 & 73.5 & 0.320 & 83.0 & 46.0 & 57.8 \\
\hline$\lambda=0.05$ & 0.316 & 97.0 & 65.9 & 75.7 & 0.21 & 94.0 & 43.0 & 53.7 \\
\hline
\end{tabular}

actual soil moisture when using the original SCS-CN method, as this parameter is crucial for calculating the amount of the direct runoff. In practice, soil moisture for normal conditions AMCII is commonly assumed, which often leads to underestimation of the catchment runoff. For example, De Paola et al. [9] suggested using AMCIII class for flow predictions when designing "sensible" structural hydraulic measures (such as detention reservoirs or floodplain storage), while for non-structural measures (such as delineation of hazard maps) this assumption may be too severe and, therefore, may require a precise evaluation of its occurrence frequency.

Figures 4 and 5 present approximation results for $P-C N_{\text {obs }}$ pairs for the second model 2-CN, and Table 5 shows the measures of its quality of fit. Similarly as in model 1, a decrease in $C N_{\text {obs }}$ was observed with increasing precipitation, and no visible stabilization of $C N_{\text {obs }}$ was noticed in either catchment. Table 4 shows the values of model 2 parameters determined during calibration. The assumed objective function was efficiency ratio $E F$ (Eq. (14)). In this model, the areas with greatest probability of runoff formation (with low retention capacity) are described by parameter $C N_{a}$, and those with high retention capacity are described by $C N_{b}$ parameter. In both catchments, $C N$ parameters were higher for $\lambda=0.20$. Based on the values of $C N_{a}, C N_{b}$ and a, $C N_{\infty}$ was calculated using the following formula:

$$
C N_{\infty}=a \cdot C N_{a}+(1-a) \cdot C N_{b}
$$

According to Ritter and Muñoz-Carpena criteria, the model was assessed as very good in the Kamienica catchment and for the Rudawa catchment it was acceptable for $\lambda=0.20$ and good for $\lambda=0.05$. A comparison of these two models demonstrated superiority of 2-CN model over model 1, as indicated by slightly higher values of $E F$ and lower RMSE for 2-CN model. This suggests that more detailed description of the catchment regarding the runoff formation, based on dividing the catchment into two zones homogeneous in terms of land cover, provides better results as far as the adoption of a single $C N$ weighted average in the catchment is concerned. In model 2 , the values of $C N_{\infty}$ in the Kamienica catchment were lower than $C N_{\text {theor }}$ for AMCII for both $\lambda$ values, and in the Rudawa catchment they were similar to AMCI.

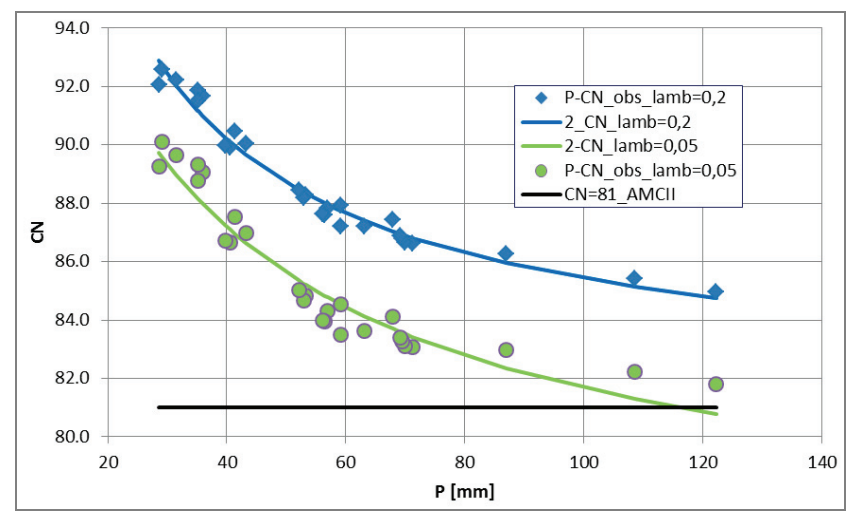

Fig. 4. $C N-P$ relationship for various values of the initial abstraction coefficient yielded with the use of model 2 in the Kamienica catchment

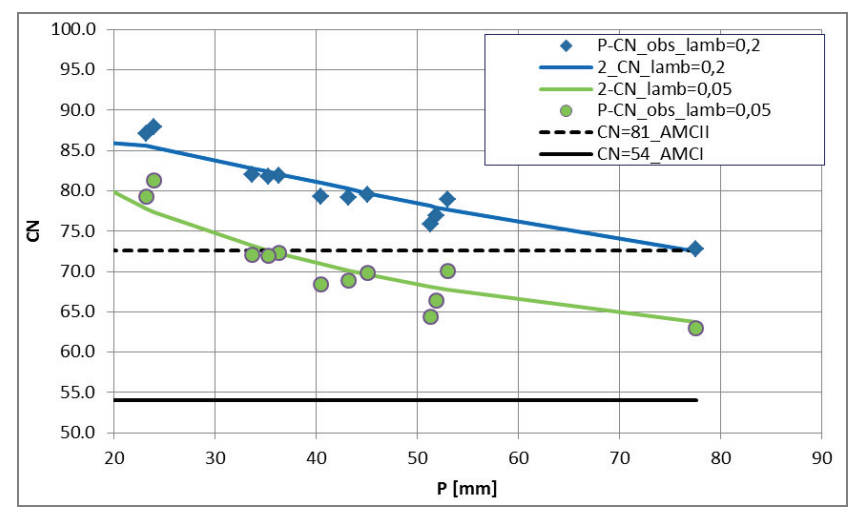

Fig. 5. $C N-P$ relationship yielded with the use of model 2 in the Rudawa catchment for various values of the initial abstraction coefficient

Direct runoff as a function of precipitation depth was calculated for both models and the outcomes are presented in Figures 6 and 7. Table 6 presents quality measures of the model with reference to $P-Q$ relationship. It is worth noting that model 2 provided more accurate outcomes of the direct runoff than the standard Hawkins model (model 1). The use of model 1 resulted in significant underestimation of the runoff, particularly for smaller precipitation. Direct runoff calculated from model 2 was very similar to that observed for the entire range of precipitation variation. This was caused by the fact that model 2 incorporated 
heterogeneous nature of the catchment in terms of land cover, and hence, permeability of the substrate. For relatively small precipitation, when the initial abstraction is exceeded, the runoff is first formed within less permeable areas. When the precipitation continues and all forms of retention are filled up, the runoff starts to form also from more permeable areas.

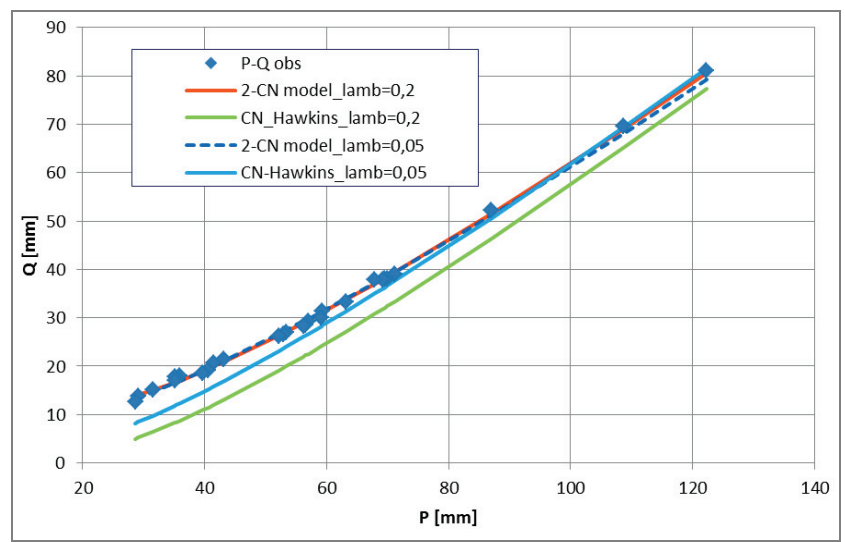

Fig. 6. Relationship between precipitation and direct runoff for various values of the initial abstraction coefficient yielded by the use of models 1 and 2 in the Kamienica catchment

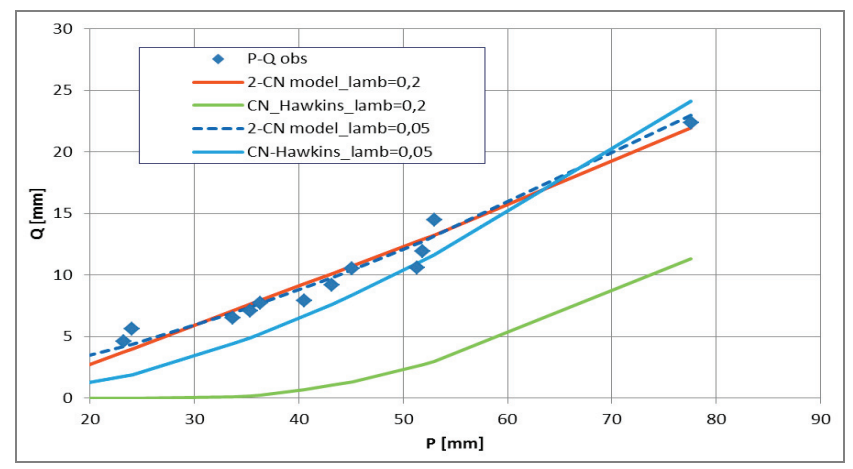

Fig. 7. Relationship between precipitation and direct runoff for various values of the initial abstraction coefficient yielded by the use of models 1 and 2 in the Rudawa catchment

In addition, considerable influence of initial soil moisture content expressed by $\lambda$ on the runoff values was observed. In both catchments and both models, much smaller runoff calculation errors, and, therefore, better model quality, was obtained for smaller initial abstraction amounting to $\lambda=0.05$. It was particularly visible in the upland catchment of the Rudawa, which further confirmed the need to verify the initial abstraction coefficient in the catchments when calculating the direct runoff according to SCS-CN method. Assumptions of the SCS-CN method [22], [23], [29], the initial abstraction coefficient of $\lambda=0.20$ is commonly used. However, many authors [2], [12], [19], [28], [32] claimed that the values of this parameter were much lower, typically reaching 0.05 .
The results presented in this study corroborated this claim.

Table 5. Quality measures of the models approximating $P-C N_{\text {obs }}$ relationship in the investigated catchments

\begin{tabular}{|l|c|c|c|c|}
\hline \multirow{2}{*}{ Model } & \multicolumn{2}{|c|}{$\begin{array}{c}\text { The Kamienica } \\
\text { catchment }\end{array}$} & \multicolumn{2}{c|}{$\begin{array}{c}\text { The Rudawa } \\
\text { catchment }\end{array}$} \\
\cline { 2 - 5 } & $\begin{array}{c}R M S E \\
{[\mathrm{~mm}]}\end{array}$ & $\begin{array}{c}E F \\
{[-]}\end{array}$ & $\begin{array}{c}R M S E \\
{[\mathrm{~mm}]}\end{array}$ & $\begin{array}{c}E F \\
{[-]}\end{array}$ \\
\hline Equation 6 for $\lambda=0.20$ & 0.426 & 0.962 & 1.175 & 0.964 \\
\hline Equation 6 for $\lambda=0.05$ & 0.761 & 0.907 & 3.091 & 0.873 \\
\hline Equation 12 for $\lambda=0.20$ & 0.364 & 0.972 & 3.404 & 0.702 \\
\hline Equation 12 for $\lambda=0.05$ & 0.648 & 0.933 & 3.087 & 0.874 \\
\hline
\end{tabular}

Table 6. Quality measures of the models approximating $P-Q$ relationship in the investigated catchments

\begin{tabular}{|l|c|c|c|c|}
\hline \multirow{2}{*}{ Model } & \multicolumn{2}{|c|}{$\begin{array}{c}\text { The Kamienica } \\
\text { catchment }\end{array}$} & \multicolumn{2}{c|}{$\begin{array}{c}\text { The Rudawa } \\
\text { catchment }\end{array}$} \\
\cline { 2 - 5 } & $\begin{array}{c}\text { RMSE } \\
{[\mathrm{mm}]}\end{array}$ & $\begin{array}{c}\text { EF } \\
{[-]}\end{array}$ & $\begin{array}{c}\text { RMSE } \\
{[\mathrm{mm}]}\end{array}$ & $\begin{array}{c}\text { EF } \\
{[-]}\end{array}$ \\
\hline Equation 6 for $\lambda=0.20$ & 7.160 & 0.793 & 7.705 & -1.556 \\
\hline Equation 6 for $\lambda=0.05$ & 3.469 & 0.951 & 2.392 & 0.753 \\
\hline Equation 12 for $\lambda=0.20$ & 0.578 & 0.998 & 1.556 & 0.896 \\
\hline Equation 12 for $\lambda=0.05$ & 0.813 & 0.997 & 1.066 & 0.951 \\
\hline
\end{tabular}

\section{CONCLUSIONS}

The authors' aim was to assess the applicability of asymptotic functions for determining the value of $C N$ parameter as a function of precipitation depth in mountain and upland catchments. To achieve this objective, three research hypotheses were put forward: i) the use of asymptotic functions enables to determine empirical values of $C N$ parameter that are much more accurate in the assessment of surface runoff formation than $C N$ values yielded by the original method, ii) $C N$ parameter significantly correlates with precipitation depth, iii) in the catchments of diversified land use, empirical values of $C N$ parameter determined with the use of 2-CN method provide better results than $C N$ defined as a weighted average value for the entire catchment.

The study analyses confirmed that asymptotic functions properly described $P-C N_{\text {obs }}$ relationship for the entire range of precipitation variability. Even though no clear stability of $C N$ parameter was observed for high precipitation, its values for small precipitation were markedly higher than those provided in USDA tables. In the case of high precipitation, $C N_{\text {obs }}$ remained 
above or below the commonly accepted average antecedent moisture conditions AMCII. The study calculations indicated that the runoff amount calculated according to the original SCS-CN method might be underestimated, which could adversely affect the values of design flows required for the design of hydraulic engineering projects. Therefore, appropriate measures are required in order to develop clear guidelines for the adoption of catchment moisture level when calculating the runoff using SCS-CN method. A strong correlation was found between the precipitation depth and empirical values of $C N_{\text {obs. }}$. Increased precipitation was followed by a reduction in $C N_{\text {obs. }}$. In catchments with heterogeneous land cover and variable substrate permeability, the results of $C N_{\text {obs }}$ were more accurate when 2-CN model was used instead of the standard Hawkins model. 2-CN model was more precise in accounting for differences in runoff formation depending on retention capacity of the substrate. This was particularly visible in the relatively flat catchment of considerable retention capacity. It was also demonstrated that the commonly accepted initial abstraction coefficient $\lambda=0.20$ yielded too big initial loss of precipitation for infiltration, evapotranspiration, interception or surface retention in the analyzed catchments and, therefore, the computed direct runoff was underestimated. The best results were obtained for $\lambda=0.05$.

\section{REFERENCES}

[1] Ajmal M., Waseem M., Wi S., Kim T.-W., Evolution of a parsimonious rainfall-runoff model using soil moisture proxies. J. of Hydrology, 2015, 530, 623-633.

[2] Baltas E.A., Dervos N.A., Mimikou M.A., Technical Note: Determination of the SCS initial abstraction ratio in an experimental watershed in Greece, Hydrol. Earth Syst. Sci., 2007, 11, 1825-1829.

[3] BANASIK K., WOODWARD D.E., Empirical determination of runoff Curve Number for a small agriculture catchment in Poland, Proceedings of the 2nd Joint Federal Interagency Conference, Las Vegas, NV, USA, 27 June-1 July 2010.

[4] BANAsIK K., RutKowsKa A., KoHnovÁ S., Retention and Curve Number Variability in a Small Agricultural Catchment: The Probabilistic Approach, Water, 2014a, 6, 1118-1133.

[5] Banasik K., Krajewski A., Sikorska A., Hejduk L., Curve Number estimation for a small urban catchment from recorded rainfall-runoff events, Archives of Environmental Protection, 2014b, 40(3), 75-86.

[6] Chauhan M.S., Kumar V., Rahul A.K., Modelling and quantifying water use efficiency for irrigation project and water supply at large scale, Int. J. Adv. Sci. Tech. Res., 2013, 3, 617-639.

[7] CHEN C.L., An evaluation of the mathematics and physical significance of the Soil Conservation Service curve number procedure for estimating runoff volume, Proc., Int. Symp. on Rainfall-Runoff Modeling, Water Resources Publ., Littleton, Colo., 1982, 387-418.
[8] Deshmukh D.S., Chaube U.C., Hailu A.E., Gudeta D.A., KASSA M.T., Estimation and comparison of curve numbers based on dynamic land use land cover change, observed rainfall-runoff data and land slope, J. Hydrol., 2013, 492, 89-101.

[9] De Paola F., Ranucci A., Feo A., Antecedent moisture condition (SCS) frequency assessment: A case study in southern Italy, Irrig. Drain., 2013, 62, 61-71.

[10] EpPS T.H., HitchCock D.R., JaYAKARAN A.D., Loflin D.R., Williams T.M, AmatYa D.M., Curve Number derivation for watersheds draining two headwater streams in lower coastal plain South Carolina, USA. J. of American Water Resources Association (JAWRA), 2013, 49(6), 1284-1295.

[11] Hawkins R.H., Asymptotic determination of Curve Numbers from data, Journal of Irrigation and Drainage Division, 1993, 119(2), 334-345.

[12] Hawkins R.H., Jiang R., WoOdward D.E., HJelmfelt A.T., Van Mullem J.A., QuAN Q.D., Runoff Curve Number Method: Examination of the Initial Abstraction Ratio, Proceedings of the Second Federal Interagency Hydrologic Modeling Conference, Las Vegas, Nevada, U.S. Geological Survey, Lakewood, Colorado, ASCE Publications 2002.

[13] King K.W., BALOGH J.C., Curve numbers for golf course watersheds, American Society of Agricultural and Biological Engineers, 2008, 51(3), 987-996.

[14] Kowalik T., WalęGA A., Estimation of CN Parameter for Small Agricultural Watersheds Using Asymptotic Functions, Water, 2015, 7(3), 939-955.

[15] KrZANOWSKi S., Miler A.T., WALEGa A., The effect of moisture conditions on estimation of the CN parameter value in the mountain catchment, Infrastruct. Ecol. Rural Areas, 2013, 3, 105-117, (in Polish).

[16] Malone R.W., Yagow G., Baffaut C., Gitau M.W., Qi Z., AMATYa D.M., Parajuli P.B., Bonta J.V., GreEN T.R., Parameterization guidelines and considerations for hydrologic models, Transaction of the ASABE, 2015, 58(6), 1681-1703.

[17] Michel C., VAZKen A., PerRIN C., Soil conservation service curve number method: how to mend a wrong soil moisture accounting procedure, Journal of Water Resources Research, 2005, 41, 1-6.

[18] Mishra S.K., Singh V.P., SCS-CN-based hydrologic simulation package, [in:] V.P. Singh, D.K. Frevert (Eds.), Mathematical Models of Small Watershed Hydrology and Applications, Water Resources Publs., LLC, Highlands Ranch, 2002, 391-464.

[19] Mishra S.K., SingH V.P., Long-term hydrological simulation based on the Soil Conservation Service curve number, J. Hydrol. Process., 2004, 18, 1291-1313.

[20] NASH J.E., SUTCLIFFE J.V., River flow forecasting through conceptual models. Part I - a discussion of principles, J. of Hydrol., 1970, 10(3), 282-290.

[21] Ponce V.M., Engineering Hydrology: Principles and Practices, Prentice Hall, Upper Saddle River, New Jersey, 1989.

[22] Ponce V.M., Hawkins R.H., Runoff curve number: Has it reached maturity? J. Hydrol. Eng., 1996, 1(1), 11-19.

[23] Rallison R.E., Miller N., Past, present, and future SCS runoff procedure. In: Rainfall-runoff relationship, Proc. of the International Symphosium on Rainfall-Runoff Modelling, Missisipi, Missisipi State University, 18-21 May 1981, 353-364. 
[24] RitTer A., Muñoz-Carpena R., Performance evaluation of hydrological models: statistical significance for reducing subjectivity in goodness-of-fit assessments, J. of Hydrol., 2013, 480, 33-45.

[25] RutKowska A., Kohnová S., Banasik K., Szolgay J., KARABOWÁ B., Probabilistic properties of a curve number: A case study for small Polish and Slovak Carpathian Basins, Journal of Mountain Science, 2015, 12(3), 533-548.

[26] SAhu R.K., Mishra S.K., Eldho T.I., Performance evaluation of modified versions of SCS curve number method for two watersheds of Maharashtra, India, ISH J. Hydraul. Eng., 2012, 18(1), 27-36.

[27] Soulis K.X., ValiantZas J.D., SCS-CN parameter determination using rainfall-runoff data in heterogeneous watersheds - the two-CN system approach, Hydrology and Earth System Sciences, 2012, 16, 1001-101.

[28] Soulis K.X., VAliantZas J.D., Identification of the SCS-CN Parameter Spatial Distribution Using Rainfall-Runoff Data in Heterogeneous Watersheds, Water Resour Manage, 2012, $27,1737-1749$.
[29] USDA Natural Resources Conservation Service. Hydrology, [in:] National Engineering Handbook; USDA Soil Conservation Service: Washington, DC, USA, 2004, Chapter 9.

[30] WalĘGa A., RutKowska A., Usefulness of the Modified NRCS-CN Method for the Assessment of Direct Runoff in a Mountain Catchment, Acta Geophysica, 2015, 63(5), 1423-1446.

[31] Walęga A., Michalec B., Cupak A., Grzebinoga M., Comparison of SCS-CN Determination Methodologies in a Heterogeneous Catchment, Journal of Mountain Science, 2015, 12(5), 1084-1094.

[32] Woodward D.E., Hawkins R.H., Jiang R., HJelmfelt A.T. JR., Van Mullem J.A., Quan D.Q., Runoff Curve Number Method: Examination of the Initial Abstraction Ratio, World Water and Environ. Resour. Congress and Related Symposia, EWRI, ASCE, 23-26 June, 2003, Philadelphia, Pennsylvania, USA.

[33] Ven Te Chow, Maidment D.K., Mays L.W., Applied of Hydrology, McGraw Hill Book Company, New York 1988. 